\title{
Syngas Quality as a Key Factor in the Design of an Energy-Efficient Pyrolysis Plant for Scrap Tyres ${ }^{+}$
}

\author{
Dina Czajczyńska ${ }^{1, *}$, Renata Krzyżyńska ${ }^{1}$ and Hussam Jouhara ${ }^{2}$ \\ 1 Wroclaw University of Science and Technology, Faculty of Environmental Engineering, \\ Wyb. Wyspianskiego 27, 50-370 Wroclaw, Poland; renata.krzyzynska@pwr.edu.pl \\ 2 Institute of Energy Futures, College of Engineering, Design and Physical Sciences, Brunel University \\ London, Uxbridge, Middlesex, London UB8 3PH, UK; hussam.jouhara@brunel.ac.uk \\ * Correspondence: dina.czajczynska@pwr.edu.pl; Tel.: +48-785038189 \\ + Presented at the 2nd International Research Conference on Sustainable Energy, Engineering, Materials and \\ Environment (IRCSEEME), Mieres, Spain, 25-27 July 2018.
}

Published: 6 November 2018

\begin{abstract}
In 20164.94 million tonnes of tyres were produced. Each tyre eventually become waste and pyrolysis has been considered an effective way of utilizing scrap tyres for several decades. However, pyrolysis has failed many times because the process has a great energy demand and the quality of products is unstable or insufficient for commercial use. Usually plants are focused on the production of pyrolytic oil or char and the gaseous phase is only a by-product. In this paper the importance of composition and quality of pyrolytic gas is emphasized. The main chemical properties make this gas a valuable biofuel that may satisfy energy requirements of the whole process (except for the start-up phase). Available data from literature concerning composition and other features of the pyrolytic gas from scrap tyres obtained at temperatures up to $1000^{\circ} \mathrm{C}$ are compared with experimental results. The quality of evolved gases is discussed in the context of the Industrial Emissions Directive (IED), too. Finally, an analysis of the mass balances obtained allows a decision about the business profile and profitability.
\end{abstract}

Keywords: waste tyres; pyrolytic gas; gaseous emissions

\section{Introduction}

Globally the demand for cars has been rising consistently for many years, thus the problem with utilizing them after exploitation is urgent. According to the European Tyre \& Rubber Manufacturers' Association, 4.94 million tonnes of tyres were produced in 2016 [1]. All of them eventually will become a difficult-to-utilize waste since they are generally very durable. Pyrolysis has been considered as an effective way to utilize scrap tyres for several decades, because it provides an opportunity of extracting valuable materials contained in tyres as well as releasing the energy from them. Additionally, emissions of pollutants such as polyaromatic hydrocarbons (PAHs) and $\mathrm{CO}_{2}$ are minimized, thus it is an environmentally respectable solution [2].

In general, the process is usually focused on the production of oil or activated carbon from the solid residue [2-7]. This is mainly because of the relatively good qualities of the liquid phase from pyrolysis, which may be used as a fuel after removing the redundant sulphur. The heating value of pyrolytic gas can reach even $44 \mathrm{MJ} / \mathrm{kg}$, which is comparable with that of commercial fuels [8]. Moreover, the variety of valuable chemicals such as BTX (benzene, toluene, xylene), limonene, ethylbenzene contained in the pyrolysis oil, make it even more interesting for investors. However, the production of sorption materials from pyrolysis char is the most popular way of utilizing pyrolysis products. Active carbon with BET surface area over $1000 \mathrm{~m}^{2} / \mathrm{g}$ has been successfully produced from waste tyres, and its effective sorption of many different substances has been proved [9]. 
On the other hand, it must be mentioned that pyrolysis is a process featuring a high energy consumption. As a result, waste tyre pyrolysis plants should be designed in a way that allows the use of the energy from the released syngas. In the first stage of the process, a reactor can be heated by combusted natural gas and then it may be fueled by the gases evolving. As reported by Aylón et al. [10] the amount of energy obtained through the combustion of the pyrolytic gas can cover all heating demands of the process, as well as to compensate for some heat losses. However, the quality of exhaust gases from scrap tyre pyrolysis should meet the EU requirements listed in the IED [11]. In this work the quality of pyrolytic gas will be examined in this wider context.

\section{Materials and Methods}

Tyre pieces of three different sizes were collected from the recycling company "Recykl" located in Greater Poland. The smallest fraction with an average particle size around $0.5 \mathrm{~cm}$ was chosen for the experiment. The samples were retrieved from whole tyres, thus they contained vulcanized rubber as well as steel and fabrics.

Tyre piece samples (each of $40 \mathrm{~g}$ ) were placed into the pyrolysis chamber. The chamber was flushed with a nitrogen flow of $2 \mathrm{~L} / \mathrm{min}$ for $2 \mathrm{~min}$ and then a constant flow of nitrogen was maintained. The settled heating rate was $5{ }^{\circ} \mathrm{C} / \mathrm{min}$. The sample was kept at the desired temperature $\left(400{ }^{\circ} \mathrm{C}, 500{ }^{\circ} \mathrm{C}\right.$ or $\left.600{ }^{\circ} \mathrm{C}\right)$ for two hours in order to process all organic materials. Vapours released were continuously cooled down and collected inside the ice trap. In some experiments syngas was collected in Tedlar ${ }^{\circledR}$ Bags using a vacuum chamber and then sent for analysis, whereas in others gas was released to the atmosphere through the scrubber. The experimental set-up with the scrubber is shown in Figure 1.

Gases evolving during the pyrolysis were investigated in a gas chromatograph (GS) equipped with Thermal Conductivity Detector (TCD) and Flame Ionization Detector (FID). Additionally, in order to prepare mass balances solid residues and oils collected from the process were weighed. The amount of evolved gases was calculated from the difference in mass between the original samples and that of solid and liquid residues.

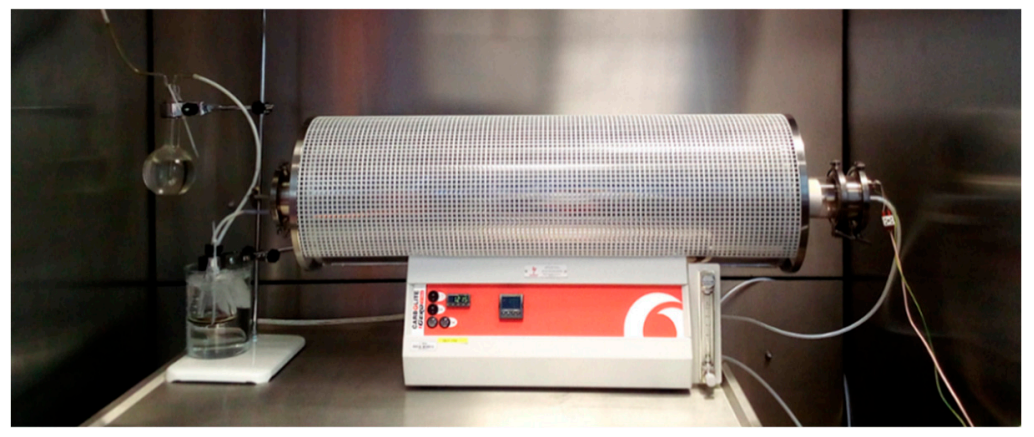

Figure 1. Experimental set-up.

\section{Results}

\subsection{Gas Composition}

The evolved gaseous mixture obtained from the pyrolysis of waste tyres was examined several times and then carefully reviewed by Williams [12]. It is possible to assume, that the mixture consists of methane and other hydrocarbons (mainly paraffins and olefins), carbon oxides, hydrogen and small amounts of impurities. Approximately 20 vol.\% of the gas is methane [12]. Additionally, pyrolytic gas contains noticeable amount of hydrogen sulfide $\left(\mathrm{H}_{2} \mathrm{~S}\right)$ which is highly corrosive.

In this work gas chromatography analysis showed the presence of compounds such as methane, ethylene, ethane, hydrogen or carbon monoxide. The GC/FID analysis results are shown in Appendix A. However, further analysis should be made since the concentration of particular components was influenced by the high concentration of nitrogen, for which a constant flow was maintained. 


\subsection{Mass Balances}

The yields of pyrolytic gas varied significantly depending on the parameters of the process, especially temperature. The mass balances obtained from the pyrolysis at three different temperatures are shown in Figure 2. As can be seen from the diagram, the amounts of gases produced decreased with increasing temperature from 400 to $600^{\circ} \mathrm{C}$. Temperatures around $600^{\circ} \mathrm{C}$ are the most suitable for maximizing oil production, whereas at $400{ }^{\circ} \mathrm{C}$ the yields of char were the highest. However, at higher temperatures (up to $1000{ }^{\circ} \mathrm{C}$ ) the production of gas increased as a result of the thermal cracking of pyrolytic oil [12].

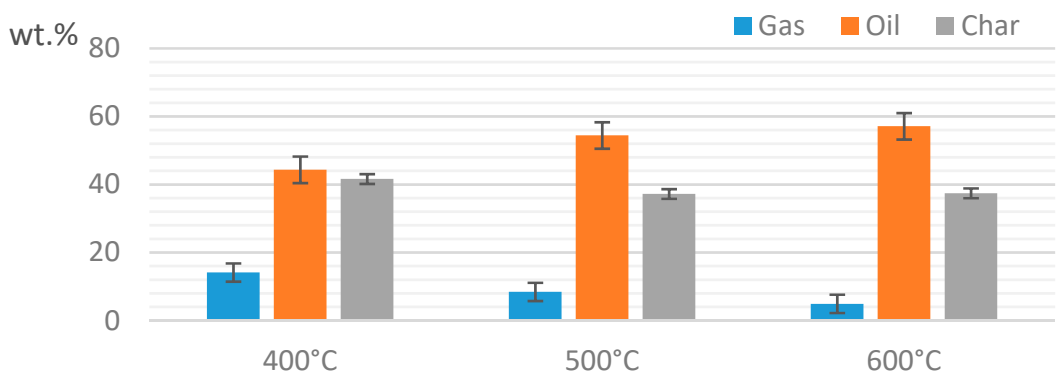

Figure 2. Gas, oil and char yields obtained at different temperatures of pyrolysis.

\section{Discussion and Conclusions}

Pyrolysis has a great potential to become a popular method of waste tyre utilization, which may attract many investors. However, several issues need to be carefully considered. Firstly, parameters of the process should be chosen optimally to ensure efficient production of the desired products. The literature contains much useful information about factors that allow optimal plant configuration. Pyrolysis gas always accompanies the production of oil or char, thus its potential should not be wasted.

Previous research and this work show that pyrolysis gas from scrap tyres consists of flammable gases with a relatively high heating value. This was reported to be as high as $81.6 \mathrm{MJ} / \mathrm{m}^{3}$ [13], although usually it varies between 30 and $40 \mathrm{MJ} / \mathrm{m}^{3}$. On-site utilization of pyrolytic gas in the waste tyre pyrolysis plant may significantly enhance the profitability of the business.

However, the environmental issues must be considered too. According to the IED [11], pyrolysis of scrap tyres is considered as combustion of waste, thus it is obliged to keep a very high quality of exhaust gases. Concentrations of $\mathrm{SO}_{2}, \mathrm{NO}, \mathrm{HCl}, \mathrm{HF}$, heavy metals, dioxins and other substances must be controlled. According to Aylón et al. [10] some of those will exceed limits (especially for $\mathrm{SO}_{2}$ emissions), when pyrolytic gas is being combusted. Thus, proper flue gas cleaning methods should be implemented. However, if the operator can prove that the quality of exhaust gases will not be lower than from natural gas, it does not have to control all those parameters [11].

Moreover, the appearance of $\mathrm{H}_{2} \mathrm{~S}$ in the raw gas obligate the designer to use very durable and expensive devices to prevent corrosion. It is expected that additional guidelines will appear soon containing limits of $\mathrm{H}_{2} \mathrm{~S}$ in gas that fuels the engines. In conclusion, the designer should choose either flue gas cleaning or raw pyrolytic gas quality enhancement. Nevertheless, the importance of syngas quality must be taken into account during the investment planning and design.

Author Contributions: D.C. and R.K. conceived and designed the experiments; D.C. performed the experiments; D.C. and R.K. analyzed the data; D.C., R.K. and H.J. wrote the paper.

Acknowledgments: The study was financed from project No. 0402/0129/17 and supported by the Department of Air Conditioning, Heating, Gas Engineering and Air Protection, Wroclaw University of Science and Technology. Many thanks to Janusz Czajczyński for his help in experiments preparation and conduction.

Conflicts of Interest: The authors declare no conflict of interest. 


\section{Appendix A}

Table A1. Results of GC/FID analysis.

\begin{tabular}{cccccccc}
\hline \multirow{2}{*}{ Retention Time (min) } & \multirow{2}{*}{ Compound } & \multicolumn{3}{c}{ Peak Area (\%) } & \multicolumn{3}{c}{ Peak Area (\%) } \\
\cline { 3 - 8 } & & $\mathbf{3 9 0}$ & $\mathbf{4 8 6}$ & $\mathbf{5 7 7}$ & $\mathbf{3 9 0}$ & $\mathbf{4 8 6}$ & $\mathbf{5 7 7}$ \\
\hline 1.12 & Methane, $\mathrm{CH}_{4}$ & 26.22 & 19.38 & 4.38 & 2.68 & 30.49 & 32.75 \\
1.42 & Ethylene, $\mathrm{C}_{2} \mathrm{H}_{4}$ & 29.18 & 7.74 & 4.62 & 2.99 & 12.18 & 34.58 \\
1.53 & Ethane, $\mathrm{C}_{2} \mathrm{H}_{6}$ & 24.02 & 8.42 & & 2.46 & 13.25 & \\
3.27 & Acetaldehyde & 35.18 & 15.19 & 3.32 & 3.60 & 23.91 & 24.82 \\
6.43 & Ethanol & 781.82 & 12.82 & & 80.02 & 20.17 \\
11.27 & Acetone & 18.15 & n. d. & & 1.85 & - & \\
\hline
\end{tabular}

\section{References}

1. ETRMA European Tyre \& Rubber Industry. Statistics Edition 2017 N.9; ETRMA: Brussels, Belgium, 2017.

2. Hita, I.; Arabiourrutia, M.; Olazar, M.; Bilbao, J.; Arandes, J.M.; Castaño Sánchez, P. Opportunities and barriers for producing high quality fuels from the pyrolysis of scrap tires. Renew. Sustain. Energy Rev. 2016, 56, 745-759, doi:10.1016/j.rser.2015.11.081.

3. Rofiqul Islam, M.; Haniu, H.; Rafiqul Alam Beg, M. Liquid fuels and chemicals from pyrolysis of motorcycle tire waste: Product yields, compositions and related properties. Fuel 2008, 87, 3112-3122, doi:10.1016/j.fuel.2008.04.036.

4. Choi, G.G.; Jung, S.H.; Oh, S.J.; Kim, J.S. Total utilization of waste tire rubber through pyrolysis to obtain oils and $\mathrm{CO}_{2}$ activation of pyrolysis char. Fuel Process. Technol. 2014, 123, 57-64, doi:10.1016/j.fuproc.2014.02.007.

5. Choi, G.G.; Oh, S.J.; Kim, J.S. Non-catalytic pyrolysis of scrap tires using a newly developed two-stage pyrolyzer for the production of a pyrolysis oil with a low sulfur content. Appl. Energy 2016, 170, 140-147, doi:10.1016/j.apenergy.2016.02.119.

6. Wang, W.C.; Bai, C.J.; Lin, C.T.; Prakash, S. Alternative fuel produced from thermal pyrolysis of waste tires and its use in a diesel engine. Appl. Therm. Eng. 2016, 93, 330-338, doi:10.1016/j.applthermaleng.2015.09.056.

7. Antoniou, N.; Stavropoulos, G.; Zabaniotou, A. Activation of end of life tyres pyrolytic char for enhancing viability of pyrolysis-Critical review, analysis and recommendations for a hybrid dual system. Renew. Sustain. Energy Rev. 2014, 39, 1053-1073, doi:10.1016/j.rser.2014.07.143.

8. Roy, C.; Chaala, A.; Darmstadt, H. Vacuum pyrolysis of used tires end-uses for oil and carbon black products. J. Anal. Appl. Pyrolysis 1999, 51, 201-221, doi:10.1016/S0165-2370(99)00017-0.

9. Mui, E.L.K.; Ko, D.C.K.; McKay, G. Production of active carbons from waste tyres-A review. Carbon N. Y. 2004, 42, 2789-2805, doi:10.1016/j.carbon.2004.06.023.

10. Aylón, E.; Murillo, R.; Fernández-Colino, A.; Aranda, A.; García, T.; Callén, M.S.; Mastral, A.M. Emissions from the combustion of gas-phase products at tyre pyrolysis. J. Anal. Appl. Pyrolysis 2007, 79, 210-214, doi:10.1016/j.jaap.2006.10.009.

11. European Council. Directive 2010/75/EU of the European Parliament and of the Council of 24 November 2010 on industrial emissions (integrated pollution prevention and control). Off. J. Eur. Union 2010, L334, doi:10.3000/17252555.L_2010.334.eng.

12. Williams, P.T. Pyrolysis of waste tyres: A review. Waste Manag. 2013, 33, 1714-1728, doi:10.1016/j.wasman.2013.05.003.

13. Laresgoiti, M.F.; de Marco, I.; Torres, A.; Caballero, B.; Cabrero, M.A.; Chomón, M.J. Chromatographic analysis of the gases obtained in tyre pyrolysis. J. Anal. Appl. Pyrolysis 2000, 55, 43-54, doi:10.1016/S01652370(99)00073-X.

(C) 2018 by the authors. Licensee MDPI, Basel, Switzerland. This article is an open access article distributed under the terms and conditions of the Creative Commons Attribution (CC BY) license (http://creativecommons.org/licenses/by/4.0/). 